\title{
SOLOS E A GEOGRAFIA FÍSICA: REFLEXõES E PRÁTICAS DE ENSINO
}

\author{
Mariana Oliveira Da Costa ${ }^{(a)}$ Sarah Lawall ${ }^{(b)}$ \\ (a) Graduanda do Depart. de Geografia, Faculdade de Geografia,Universidade Federal Rural do Rio de Janeiro, \\ Email.mari.oliveira1995@ hotmail.com \\ (b) Professora do Departamento de Geociencias, Faculdade de Geografia, Universidade, Email: \\ sarahgeoprof@gmail.com
}

EIXO: GEOGRAFIA FÍSICA: CURRÍCULO, FORMAÇÃO E PRÁTICAS DE ENSINO

\begin{abstract}
Resumo
Solo é um recurso natural finito e com inúmeras funções sociais e ecológicas. O estudo da origem, evolução e diversidade deve transcender o ensino superior e chegar, com devida importância, no ensino fundamental e médio. Afinal, de que forma estamos aprendendo e ensinando a pedologia? Assim, objetiva-se estabelecer uma reflexão acerca do ensino de solos na Geografia com base na reflexão fruto do resultado de oficina didática acerca dos processos de formação do solo. Para método, tem-se etapas de construção de perfis de solos utilizando caixa de isopor e diferentes amostras de solos, estabelecendo evolução temporal que auxiliem na prática cotidiana escolar. Esta oficina foi aplicada junto aos alunos do PIBID e Pedologia aplicada a Geografia. Considera-se que a ciência do solo é fundamental e não deve ser coadjuvante dentre os conteúdos da Geografia e que há a necessidade de maior envolvimento do profissional de licenciatura na ciência do solo.
\end{abstract}

Palavras chave: pedologia, métodos, didática, formação dos solos

\section{Introdução}

Como aprendemos e/ou lecionamos a temática sobre os solos na Geografia escolar? Compete a Geografia o processo de ensino-aprendizagem a respeito da ciência do solo? De que forma os currículos da Geografia contribuem para aprender e ensinar o processo de formação dos solos? De forma geral, o estudo da Ciência dos Solos ou Pedologia está destinado a grupo restrito de estudantes de graduação nos cursos que competem o saber pedológico, ou seja, das ciências agronômicas, passando as ciências da Terra e Engenharias. Para os currículos de licenciatura, e em especial de Geografia, a Pedologia ou Ciência do Solo vem se diluindo e incorporando-se nos conteúdos de Geomorfologia. Poucos são os centros que oferecem pedologia na licenciatura.

Este processo pode desencadear duas perspectivas conflitantes: o professor mal-formado e a desvalorização da pedologia na base escolar, ou seja, no Fundamental e Médio. No ensino fundamental e médio, pouca ênfase é dada a ciência do solo os quais os conteúdos estão contidos 
em subítens do $6^{\circ}$ ano e $1^{\mathrm{a}}$ série, respectivamente, vinculados a temática descontextualizada de relevo e também nos impactos ambientais, muito relacionado aos processos erosivos por atividade antrópica. Porém, qual é a importância de se estudar solos na Geografia?

Deve-se pensar que o solo é tido como recurso natural essencial para a manutenção da vida porque é dele que extrairmos os alimentos, a partir da atividade agrícola (Bertoni e Lombardi Neto,2008). No entanto, é preciso ir além e reconhecer que sua importância na Geografia está intimamente relacionada ao seu conceito como escrito no Soil Survey Manual (1951) definindo solo como um corpo natural pertencente a paisagem, fruto da combinação de fatores geográficos locais-regionais e que está em constante alteração, tanto no tempo e quanto no espaço. A Geografia também se faz presente quando pensa-se que o solo não é usado apenas para agricultura, existem outras demandas humanas, afinal, é nele que pisamos, construímos nossas casas, cidades, estradas e também é dele que extraímos parte da matéria prima para construção civil (Lepsh, 2011).

Além disso, solos tem a função de conservação dos ecossistemas porque sustentam as plantas, abrigam infinita micro, meso e macrofauna do solo responsável pela produção de matéria orgânica, mantem ativos os ciclos biogeoquímicos, recarregam os aquíferos e mantem o curso perene das águas dos rios (Thoeh e Thompson, 2007). A partir das múltiplas funções ecológicas e sociais que os solos possuem nos conduzem a reflexão da importância da pedologia no ambiente escolare principalmente, o aluno/professor precisa entender o processo de formação dos solos para depois relacionar as demais questões e funções. A Geografia aparece como suporte a esta compreensão porque é uma ciência relacional, da mesma forma na educação ambiental estabelecendo a consciência ecológica (Frasson e Werlang, 2010).

Neste sentido, os objetivos deste trabalho pautam-se na reflexão acerca do ensino de solos na Geografia a partir da prática de ensino veiculada na forma de oficina didática com tema acerca dos processos de formação do solo (pedogenéticos). Estes passos são fundamentais para a inserção de outras práticas tanto no processo de formação do professor quanto no dia a dia do cotidiano escolar. Nesse sentido, será possível analisar na formação da maquete o conceito de solo; os fatores que contribuem para a sua formação; os horizontes que são gerados; a importância que esse recurso natural possui para o meio ambiente; as funções que ele exerce na natureza e as consequências que podem ocorrer devido à intensificação do seu uso pelo homem. 


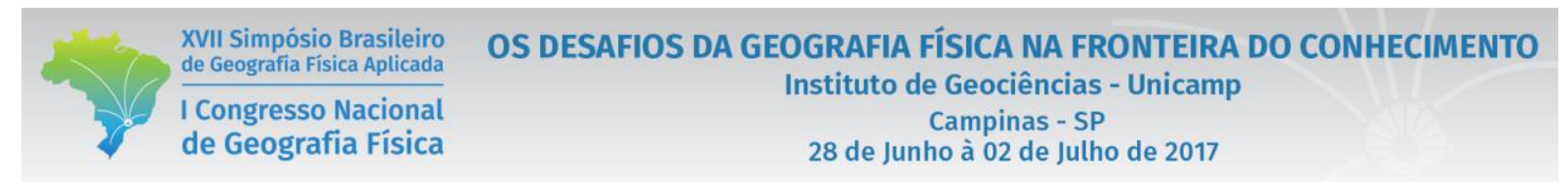

\section{Metodologia}

A metodologia foi baseada na criação de uma Oficina de Formação de Solo aplicada para os bolsistas do Programa Institucional de Bolsa de Iniciação à Docência (PIBID) de Geografia na Universidade Federal Rural do Rio de Janeiro (UFRRJ), no Instituto Multidisciplinar e também como parte avaliativa da disciplina de Pedologia aplicada à Geografia. Pode-se dizer que essas oficinas foram oferecidas com a finalidade de introduzir um ensino de solo mais dinâmico e diferenciado para os discentes.

A metodologia que utilizamos para elaborar essa oficina se consiste em quatro momentos, sendo estes: 1) Abordagem do conceito de solo, entendendo que este é um corpo tridimensional, composto por minerais, ar, água e matéria orgânica, elucidando seu processo de formação a partir dos cinco fatores essenciais: material de origem, tempo, relevo, clima e organismos. 2) no segundo momento aborda-se o processo de intemperismo da rocha de origem e a evolução do solo, sob a perspectiva dos horizontes de um perfil de solo. 3) Separação do material necessário para a representação dos horizontes do solo (horizontes A; B; C) e rocha de origem, os quais serão essenciais para a confecção de uma maquete. 4) no quarto momento parti-se para a confecção da maquete. A proposta é representar a evolução temporal dos principais horizontes do solo envolvendo os processos pedogenéticos e a formação de horizontes rasos, a formação do horizonte diagnostic B e perfil complete de solos mais profundos, conforme o esquema da figura 01. Este procedimento foi realizado e indicado nas oficinas propostas do Projeto Solos na Escola, do Departamento de Ciência dos Solos, Universidade Federal do Paraná.

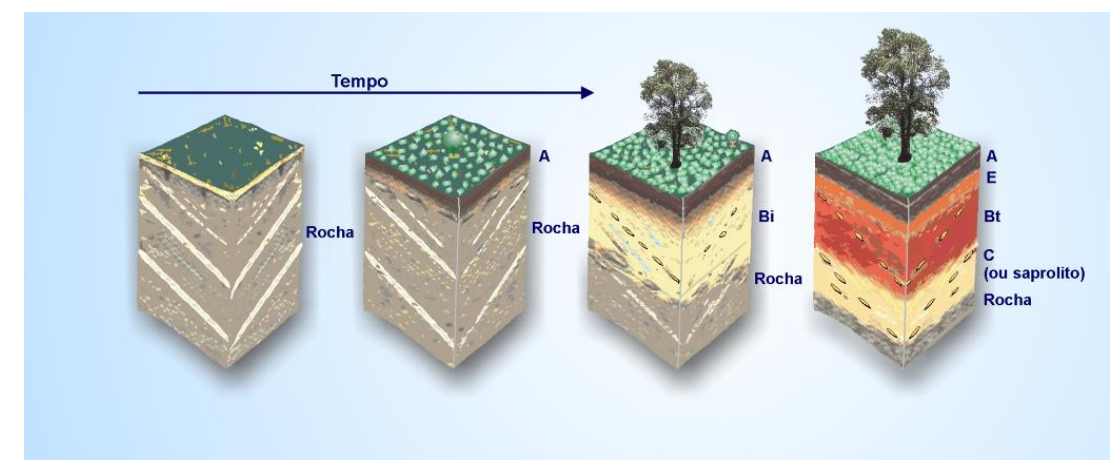

Figura 01- Representação da evolução temporal dos perfis de solos, Lepsh,2011. 
Para construir essa maquete precisa-se dos seguintes materiais: uma caixa de papelão, quatro tiras de papelão e três tipos de solos (A, B, C), podendo ser areia, argila e matéria orgânica por exemplo. Dessa forma, o processo de construção dessa maquete consiste em sete etapas, sendo que da primeira a terceira, trata-se da montagem da estrutura que será toda realizada na caixa de papelão, figura 2. Assim, foram cortadas 4 tiras de papelão da tampa da caixa de sapato. As tiras devem formar 5 divisórias, sendo essas tiras cada uma com 5 centímetros de largura e com comprimento necessário para tocar as partes dianteira e traseira da caixa. Em seguida, houve a fixação das tiras com fitas adesivas, concluindo a estrutura que receberá o processo de evolução temporal dos horizontes dos solos.

As etapas seguintes mostram a forma de preenchimento da "caixa pedogenética". Então, a primeira divisória foi exclusivamente para o material de origem, preenchendo-a completamente de rochas fragmentadas. Em seguida, a segunda divisória foi preenchida por $70 \%$ de rocha, ou seja, as rochas fragmentadas, $15 \%$ de material intemperizado e $15 \%$ de solo de horizonte A (solo de cor mais escura). $\mathrm{Na}$ terceira divisória, houve preenchimento de $1 / 3$ da quantidade de rocha original/fragmentadas e proporções iguais de horizonte $\mathrm{C}$ e horizonte $\mathrm{A}$, mostrando a formação do solum. Já na sexta etapa, a quarta divisória foi preenchida por rochas fragmentadas, horizonte C (maior que o horizonte B), horizonte B diagnóstico e horizonte A. E por fim, na última etapa A última divisória deverá ser preenchida por rocha original, rochas fragmentadas, horizonte C, horizonte B (maior que o horizonte C) e horizonte A, gerando o perfil completo de solos decorrente dos processos e fatores pedogenéticos.

\section{Considerações a respeito da aplicabilidade da Oficina didática e o ensino de solos}

A reflexão ao final da oficina realizada foi de que há a necessidade de levar essa atividade para a nossa prática docente, visto que essa proposta metodológica permitiu inserir o ensino de solo de maneira lúdica e dinâmica, figura 2. 


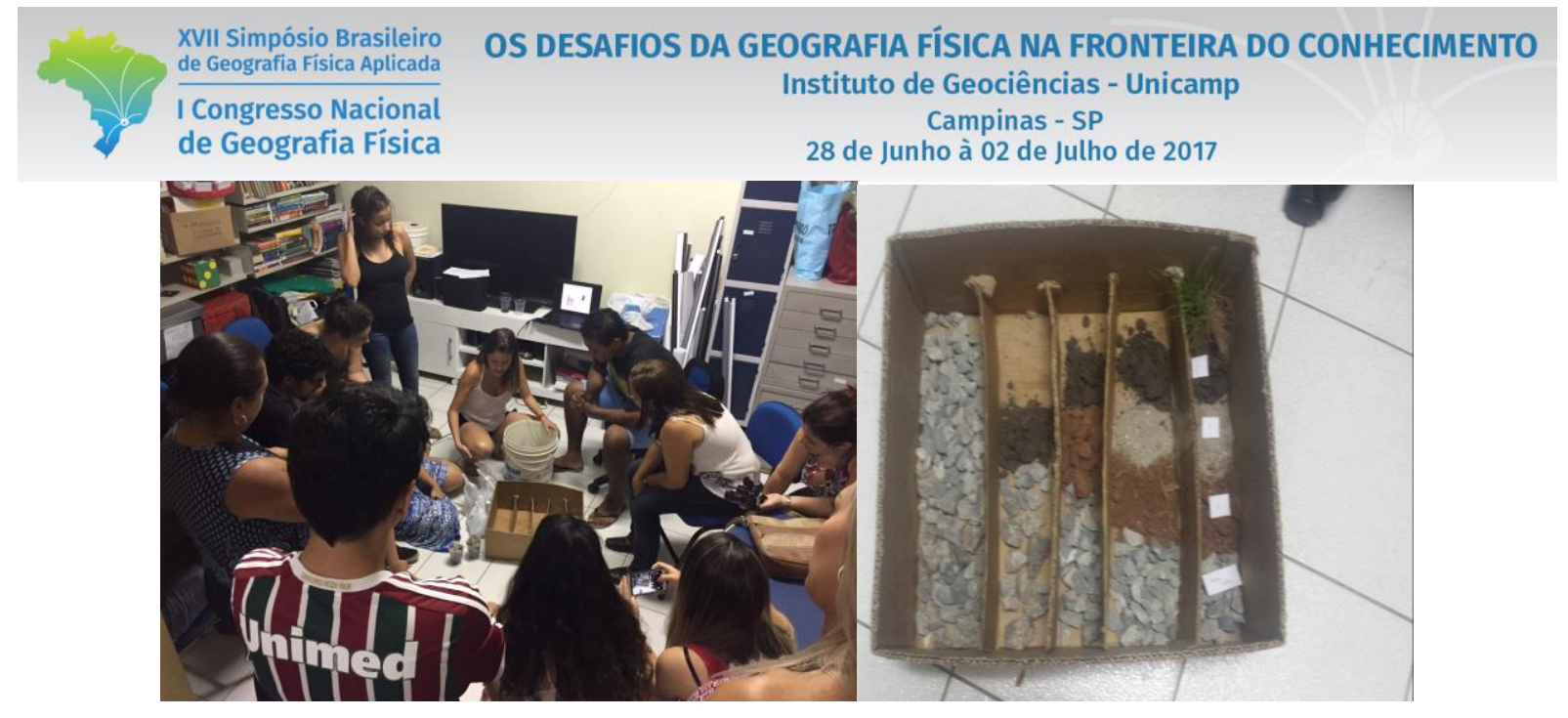

Figura 2 - Realização da Oficina Didática de Formação dos Solos no PIBID e resultado da construção da maquete. Fonte: arquivo pessoal de Oliveria, Mariana. 2016.

Da mesma forma, ficou evidenciado que o conteúdo de solos é de suma importância para o processo de formação de professores. Tanto os alunos do curso de graduação em Geografia quanto os do PIBID relataram, que a educação em solos é elementar para a formação e consolidação do espaço geográfico. Podemos observar que ao abordar a formação de solo e explicar seus fatores de formação com essa maquete facilitou a compreensão desse conteúdo pelos discentes, uma vez que eles participaram da sua construção e tiraram suas dúvidas ao longo da atividade. A oficina didática com a prática estabelecida pode ser entendida como um meio interlocutor entre a teoria e o estudo do meio, de fato, ou seja, na natureza. Desta forma, é possível romper com as dificuldades de deslocar o aluno para o meio, e sair da abstração, uma vez que paisagem é reproduzida de forma reduzida e representativa. E assim, o aluno poderá associar a representação, a realidade e teoria, fechando um ciclo básico do processo ensinoaprendizagem.

\section{REFERÊNCIAS}

BERTONI, J.; LOMBARDI NETO, F. Conservação do solo. São Paulo: Ícone, 2008.

FRASSON, V.R., WERLANG, M.K. Ensino de Solos na Perspectiva Ambiental: Contribuíções a Ciência Geográfica. Geografia: Ensino \& Pesquisa, Santa Maria, v. 1 4, n. 1, p. 94- 99, 2010

LEPSH, I.F. 19 lições de Pedologia. São Paulo: Oficina de Textos. 2011.

TROEH, F.R., THOMPSON, L.M. Solos e Fertilidade do Solo. Sao Paulo: Andrei, 2007. 